\title{
Can arterial stiffness parameters be measured in the sitting position?
}

\author{
Jens Nürnberger ${ }^{1}$, Rene Michalski², Tobias R Türk², Anabelle Opazo Saez ${ }^{1}$, Oliver Witzke ${ }^{2}$ and \\ Andreas Kribben ${ }^{2}$
}

Despite the introduction of arterial stiffness measurements in the European recommendation, pulse wave velocity (PWV) and augmentation index (AI) are still not used routinely in clinical practice. It would be of advantage if such measurements were done in the sitting position as is done for blood pressure. The aim of this study was to evaluate whether there is a difference in stiffness parameters in sitting vs. supine position. Arterial stiffness was measured in 24 healthy volunteers and 20 patients with cardiovascular disease using three different devices: SphygmoCor (Atcor Medical, Sydney, Australia), Arteriograph (TensioMed, Budapest, Hungary) and Vascular Explorer (Enverdis, Jena, Germany). Three measurements were performed in supine position followed by three measurements in sitting position. Methods were compared using correlation and Bland-Altman analysis. There was a significant correlation between PWV in supine and sitting position (Arteriograph: $P<0.0001, r=0.93$; Vascular Explorer; $P<0.0001, r=0.87)$. There were significant correlations between Al sitting and Al supine using Arteriograph $(P<0.0001$, $r=0.97)$, Vascular Explorer $(P<0.0001, r=0.98)$ and SphygmoCor $(P<0.0001, r=0.96)$. When analyzed by Bland-Altman, PWV and Al measurements in supine vs. sitting showed good agreement. There was no significant difference in PWV obtained with the three different devices (Arteriograph $7.5 \pm 1.6 \mathrm{~m} \mathrm{~s}^{-1}$, Vascular Explorer $7.3 \pm 0.9 \mathrm{~m} \mathrm{~s}^{-1}$, SphygmoCor $7.0 \pm 1.8 \mathrm{~m} \mathrm{~s}^{-1}$ ). Al was significantly higher using the Arteriograph $(17.6 \pm 15.0 \%)$ than Vascular Explorer and SphygmoCor $(10.2 \pm 15.1 \%$ and $10.3 \pm 18.1 \%$, respectively). The close agreement between sitting and supine measurements suggests that both PWV and Al can be reliably measured in the sitting position.

Hypertension Research (2011) 34, 202-208; doi:10.1038/hr.2010.196; published online 21 October 2010

Keywords: arterial stiffness; augmentation index; PWV; pluse wave velocity

\section{INTRODUCTION}

The evaluation of arterial stiffness is presently used to investigate the function of large arteries in epidemiological and clinical studies. In 2007, measurements of arterial stiffness were included into the recommendation of the European Societies for Hypertension and Cardiology for the management of patients with hypertension. ${ }^{1}$ Although pulse wave velocity (PWV) is the classical non-invasive parameter and gold standard of arterial stiffness, augmentation index (AI) quantifies the effect of wave reflection on central blood pressure., ${ }^{2,3}$

Despite the availability of non-invasive devices such as SphygmoCor and Complior, assessment of arterial stiffness has not become an established procedure in daily clinical practice. One possible reason is that the classical measurement of PWV requires access to the femoral artery for tonometry in the supine position with concurrent exposure of the inguinal area. ${ }^{4}$ This procedure is uncomfortable to the patient, is impractical, and time consuming. It would be easier if measurements of arterial stiffness could be performed in the sitting position, in the same way that blood pressure is routinely measured in daily clinical routine. ${ }^{1}$
New devices, including the Arteriograph and the Vascular Explorer, have been developed to determine PWV, AI and central blood pressure from oscillometrically recorded brachial pressure waves using an upper arm cuff. ${ }^{5,6}$ Because arterial stiffness parameters are determined from that single pressure pulse recording at the brachial artery, these new devices eliminate the intrusive procedure of obtaining a femoral pulse recording, and hence, offer the possibility of taking measurements in the sitting position. Measurements in the sitting position (ideally together with blood pressure measurements) could facilitate the use of arterial stiffness parameters in clinical routine.

However, it is not known whether posture has an influence on arterial stiffness parameters. The aim of this study was to evaluate the role of posture on PWV and AI, and to assess whether arterial stiffness measurements can be reliably measured in the supine position.

\section{METHODS}

Study population

A total of 24 healthy individuals and 20 patients with cardiovascular disease were recruited (Table 1).

${ }^{1}$ Department of Nephrology and Dialysis, HELIOS Kliniken Schwerin, Wismarsche Straße, Schwerin, Germany and ${ }^{2}$ Department of Nephrology, University Hospital Essen, University Essen-Duisburg, Hufelandstraße, Essen, Germany

Correspondence: Dr J Nürnberger, Department of Nephrology, HELIOS Kliniken Schwerin, Wismarsche Straße 393-397, Schwerin 19049, Germany.

E-mail: jens.nuernberger@uni-due.de

Received 2 May 2010; revised 25 July 2010; accepted 31 July 2010; published online 21 October 2010 
Table 1 Characteristics of the study populations (mean \pm s.d.)

\begin{tabular}{lcc}
\hline & $\begin{array}{c}\text { Healthy volunteers } \\
(\mathrm{n}=24)\end{array}$ & $\begin{array}{c}\text { Patients with } \\
\text { cardiovascular } \\
\text { disease }(\mathrm{n}=20)\end{array}$ \\
\hline Age (years) & $28 \pm 4$ & $55 \pm 17$ \\
Gender (male/female) & $16 / 8$ & $11 / 9$ \\
Height (cm) & $178 \pm 9.2$ & $172 \pm 12$ \\
Weight (kg) & $77 \pm 15$ & $76 \pm 17$ \\
Body mass index (kg m ${ }^{-2}$ ) & $24 \pm 4$ & $25 \pm 4$ \\
History or presence of hypertension & & $N=16$ \\
Presence of coronary heart disease & & $N=4$ \\
Presence of renal disease & & $N=11$ \\
\hline
\end{tabular}

Height and weight were measured, and body mass index was calculated as weight to height squared. Laboratory measurements were measured with commercially available kits in our central laboratory. The responsible ethical committee has approved the experiments, and the study was performed in accordance with the principles laid down in the Declaration of Helsinki. Participants gave their informed consent before their inclusion in the study.

\section{Hemodynamic measurements}

Measurements were performed in a quiet, temperature-controlled room after a resting period of $5 \mathrm{~min}$ in a supine position according to the recommendations for user procedures of clinical applications of arterial stiffness. ${ }^{7}$ First, three measurements were taken in the supine position at 5 min intervals for each of three devices. Then subjects changed into the sitting position followed by three measurements at $5 \mathrm{~min}$ intervals. PWV, AI and central blood pressure were measured using three commercially available devices: the SphygmoCor (AtCor Medical), the Arteriograph (Tensiomed) and the Vascular Explorer (Enverdis).

The SphygmoCor device determines PWV from sequentially recorded pressure waveforms of the carotid and femoral artery using electrocardiography for synchronization of (carotid and femoral) pulse wave times. The foot-to-foot method with the intersecting tangent algorithm was used to determine pulse transit time (PTT). Pulse wave travel distance was determined by subtracting carotid-suprasternal notch distance from suprasternal notch to femoral distance. ${ }^{8}$ PWV $\left(\mathrm{m} \mathrm{s}^{-1}\right)$ was automatically calculated as ratio between the distance traveled by the pulse wave and PTT. SphygmoCor was also used to measure AI and central pressure employing pulse wave analysis. Pressure waves were recorded from the radial artery by applanation tonometry and an averaged waveform was generated, from which central hemodynamics were automatically calculated as previously described. ${ }^{9}$

The Arteriograph and the Vascular Explorer calculate arterial stiffness parameters from oscillometrically recorded pressure waves of the brachial artery. Using inflatable upper arm cuffs with high fidelity sensors, pulsatile volume changes (resulting from pulsatile fluctuations of the brachial artery) are transduced into pressure curves. Pulse waves are recorded when the brachial artery is completely occluded at a cuff pressure that is $35-40 \mathrm{~mm} \mathrm{Hg}$ above systolic blood pressure. Computer programs are used to further analyze the recorded pulse waves.

PTT is determined from the decomposition of the generated aortic pressure wave using the reflection method. ${ }^{10}$ This measurement is based on the fact that the forward traveling pulse wave (generated by the ejection of the left ventricle) is reflected in the periphery creating a second reflected wave. PTT is determined from the difference in milliseconds between the forward and the beginning of the reflected pressure wave, and aortic PWV is automatically calculated from PTT and traveling distance between jugulum (sternal notch) and symphysis pubica (according to the manufacturers recommendations). Central hemodynamics including AI and central blood pressure were calculated from brachial pressure curves in combination with automated transfer algorithms.

\section{Statistical analysis}

Values of stiffness and hemodynamic parameters were obtained from the mean of the three measurements performed in the sitting and supine position. Paired,
Table 2 Means and s.d. of hemodynamics in supine and sitting positions

\begin{tabular}{lccc}
\hline Parameter & $\begin{array}{c}\text { Supine } \\
\text { position }\end{array}$ & $\begin{array}{c}\text { Sitting } \\
\text { position }\end{array}$ & P-value \\
\hline Peripheral SBP (mm Hg) & $132.1 \pm 15.2$ & $132.7 \pm 15.5$ & 0.4922 \\
Peripheral diastolic blood pressure & $76.6 \pm 10.3$ & $78.2 \pm 10.9$ & 0.0126 \\
(mm Hg) & & & \\
Heart rate (b.p.m.) & $67.5 \pm 11.8$ & $69.5 \pm 12.0$ & 0.0024 \\
PWV ( $\mathrm{m} \mathrm{s}^{-1}$ ) Arteriograph & $7.5 \pm 1.6$ & $7.7 \pm 1.8$ & 0.0987 \\
PWV ( $\mathrm{m} \mathrm{s}^{-1}$ ) Vascular Explorer & $7.3 \pm 0.9$ & $7.4 \pm 0.9$ & 0.1908 \\
PWV ( $\mathrm{m} \mathrm{s}^{-1}$ ) SphygmoCor & $7.0 \pm 1.8$ & - & - \\
Augmentation index (\%) Arteriograph & $17.6 \pm 15.0$ & $18.7 \pm 15.3$ & 0.0877 \\
Augmentation index (\%) Vascular & $10.2 \pm 15.1$ & $11.6 \pm 16.4$ & 0.2571 \\
Explorer & & & \\
Augmentation index at 75 (\%) & $9.7 \pm 15.5$ & $10.1 \pm 16.3$ & 0.4073 \\
Vascular Explorer & & & \\
Augmentation index (\%) SphygmoCor & $10.3 \pm 18.1$ & $11.8 \pm 16.0$ & 0.0838 \\
Augmentation index at 75 (\%) & $9.5 \pm 17.8$ & $10.6 \pm 15.8$ & 0.1921 \\
SphygmoCor & & & \\
Central SBP (mm Hg) Arteriograph & $115.3 \pm 21.8$ & $121.3 \pm 23.0$ & $<0.0001$ \\
Central SBP (mm Hg) Vascular Explorer & $116.9 \pm 19.6$ & $119.3 \pm 21.1$ & 0.0515 \\
Central SBP (mm Hg) SphygmoCor & $111.6 \pm 17.6$ & $111.3 \pm 17.5$ & 0.2126 \\
Augmentation (mm Hg) Vascular & $5.6 \pm 8.4$ & $6.8 \pm 10.5$ & 0.1210 \\
Explorer & & & \\
Augmentation (mm Hg) SphygmoCor & $4.9 \pm 8.2$ & $5.4 \pm 7.6$ & 0.0829 \\
\hline
\end{tabular}

Abbreviations: Augmentation index at 75, augmentation index normalized for heart rate; b.p.m., beats per minute; PWV, pulse wave velocity; SBP, systolic blood pressure.

Means were compared by paired $t$-test.

two-sided Student's $t$-test was used to analyze differences between supine and sitting positions. Pearson's correlation was used to assess the relationship between parameters in sitting and supine position. Bland-Altman analysis was included for comparison of parameters between positions (a difference plot combined with calculation of the 2 s.d. limits of the differences between the methods, the $95 \%$ limits of agreement). In addition, differences between methods in measuring PWV and AI were assessed using paired, two-sided Student's $t$-tests, correlation and Bland-Altman analysis. $P<0.05$ was considered statistically significant. All values are shown as mean \pm s.d. Statistical analysis was performed using GraphPad Prism 4.00 for MS Windows (GraphPad Software, San Diego, CA, USA).

\section{RESULTS}

Table 1 shows the clinical characteristics of the study population. Table 2 shows the mean values of classical hemodynamic and arterial stiffness parameters in supine and sitting position. Peripheral diastolic blood pressure, heart rate and central systolic blood pressure measured with the Arteriograph device were significantly higher in the sitting position. There was no difference in PWV or AI between sitting and supine positions regardless of the device employed. Also, AI normalized to heart rate was not statistically different between sitting and supine positions.

Figure 1 shows the results of comparisons between sitting and supine for PWV using the Arteriograph (Figures 1a and b) and the Vascular Explorer (Figures 1c and d). (This analysis was not done for measurements of the SphygmoCor as this device allows PWV measurements only in the supine position). There was a significant correlation between $\mathrm{PWV}$ in supine and sitting position using the Arteriograph (Figure 1a, $P<0.0001, r=0.93$ ), and using the Vascular Explorer (Figure 1c, $P<0.0001, r=0.87$ ). When analyzed by BlandAltman, the majority of the data points for PWV in supine $v$ s. sitting were found within the range of 2 s.d. and with an acceptable 

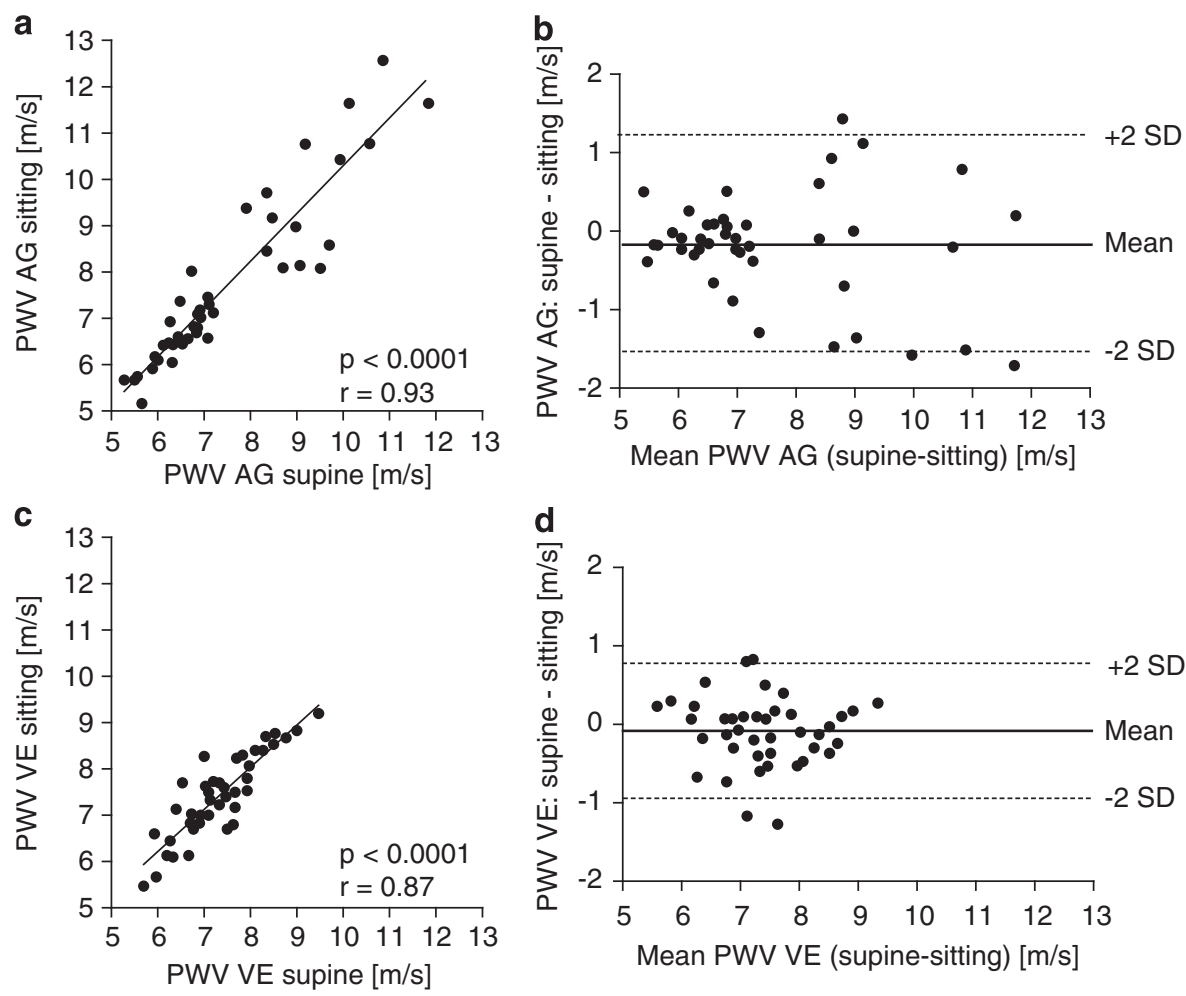

Figure 1 Correlations between sitting and supine measurements of PWV obtained using the Arteriograph (a) and the Vascular Explorer (c). Bland-Altman plots comparing sitting and supine measurements of PWV obtained by the Arteriograph (b) and the Vascular Explorer (d). AG, Arteriograph; PWV, pulse wave velocity; VE, Vascular Explorer.

correspondence of mean values (Figures $1 \mathrm{~b}$ and $\mathrm{d}$ ). Although there was no suggestion for a systematic bias, PWV values obtained by the Arteriograph showed a higher variability above $8 \mathrm{~m} \mathrm{~s}^{-1}$ compared with values lower than $8 \mathrm{~m} \mathrm{~s}^{-1}$.

The results of AI between supine and sitting position are shown in Figure 2. There were significant correlations between $\mathrm{AI}$ sitting and $\mathrm{AI}$ supine using the Arteriograph (Figure 2a, $P<0.0001, r=0.97$ ), the Vascular Explorer (Figure $2 c, P<0.0001, r=0.98$ ) and the SphygmoCor (Figure $2 \mathrm{e}, P<0.0001, r=0.96$ ). The majority of data points for AI measured in both supine and sitting lied within the range of 2 s.d. when analyzed by Bland-Altman (Figures $2 \mathrm{~b}$, d and $\mathrm{f}$ ). There was a good correspondence of mean values with an absence of a systematic bias.

We further analyzed differences among the three devices by comparing PWV and AI that were obtained in the supine position. Values for PWV and AI are shown in Table 2.

There was no significant difference between PWV measures obtained with the three different devices (Arteriograph vs. SphygmoCor, $P=0.096$; Vascular Explorer vs. SphygmoCor, $P=0.504$; Vascular Explorer vs. Arteriograph, 0.253). Figure 3 shows PWV values obtained with the three devices. There was a moderate, but significant correlation between PWV Arteriograph and SphygmoCor (Figure 3a, $P<0.0001, r=0.64)$. PWV obtained by the Vascular Explorer was also correlated to PWV obtained using SphygmoCor (Figure 3b, $P=0.0002$, $r=0.57$ ) and Arteriograph (Figure $3 c, P=0.0002, r=0.55$ ). BlandAltman analysis showed a large variability in data values with an s.d. at $1.5 \mathrm{~m} \mathrm{~s}^{-1}$ and with a systematic bias with overestimation of PWV at lower PWV values, and underestimation at higher PWV values by the Vascular Explorer. Analyzed by Bland-Altman, the large majority of values were found within the range of 2 s.d. (Figures $3 \mathrm{~b}$, $\mathrm{d}$ and $\mathrm{f}$ ).
AI determined with the Arteriograph was significantly higher than AI obtained with the SphygmoCor or the Vascular Explorer (Table 2, $P<0.0001$ for both comparisons). There was no difference in the AI between SphygmoCor and Vascular Explorer $(P=0.9698)$.

Figure 4 shows AI measured with the three devices. Significant correlations were found between Arteriograph and SphygmoCor (Figure 4a, $P<0.0001, r=0.90$ ), Vascular Explorer and SphygmoCor (Figure $4 c, P<0.0001, r=0.89$ ), and Vascular Explorer and Arteriograph (Figure $4 \mathrm{e}, P<0.0001, r=0.97$ ).

There was an acceptable correspondence of mean values with smallest s.d. for the comparison of the oscillometric devices (Arteriograph and Vascular Explorer). Bland-Altman analysis showed that the large majority of data points were found within the range of 2 s.d. Results suggest a systematic bias for AI, which appeared to be overestimated by the SphygmoCor device for values below $0 \%$ compared with the Arteriograph and Vascular Explorer (Figures 4a-d).

Results were not different when groups were split into healthy subjects and patients with cardiovascular disease (data not shown).

\section{DISCUSSION}

The aim of the study was to compare indices of arterial stiffness (PWV) and wave reflection (AI) measured in supine position with those measured in sitting position to explore whether posture influences arterial stiffness parameters. Stiffness measurements in the sitting position would allow simultaneous measurements of blood pressure and heart rate as they should be obtained in sitting position according to the current guidelines. ${ }^{1}$ Even though we found that measurements of PWV and AI were not significantly different between supine and sitting position, posture influences hemodynamic regulation. For instance, it has been shown that body position slightly affects 

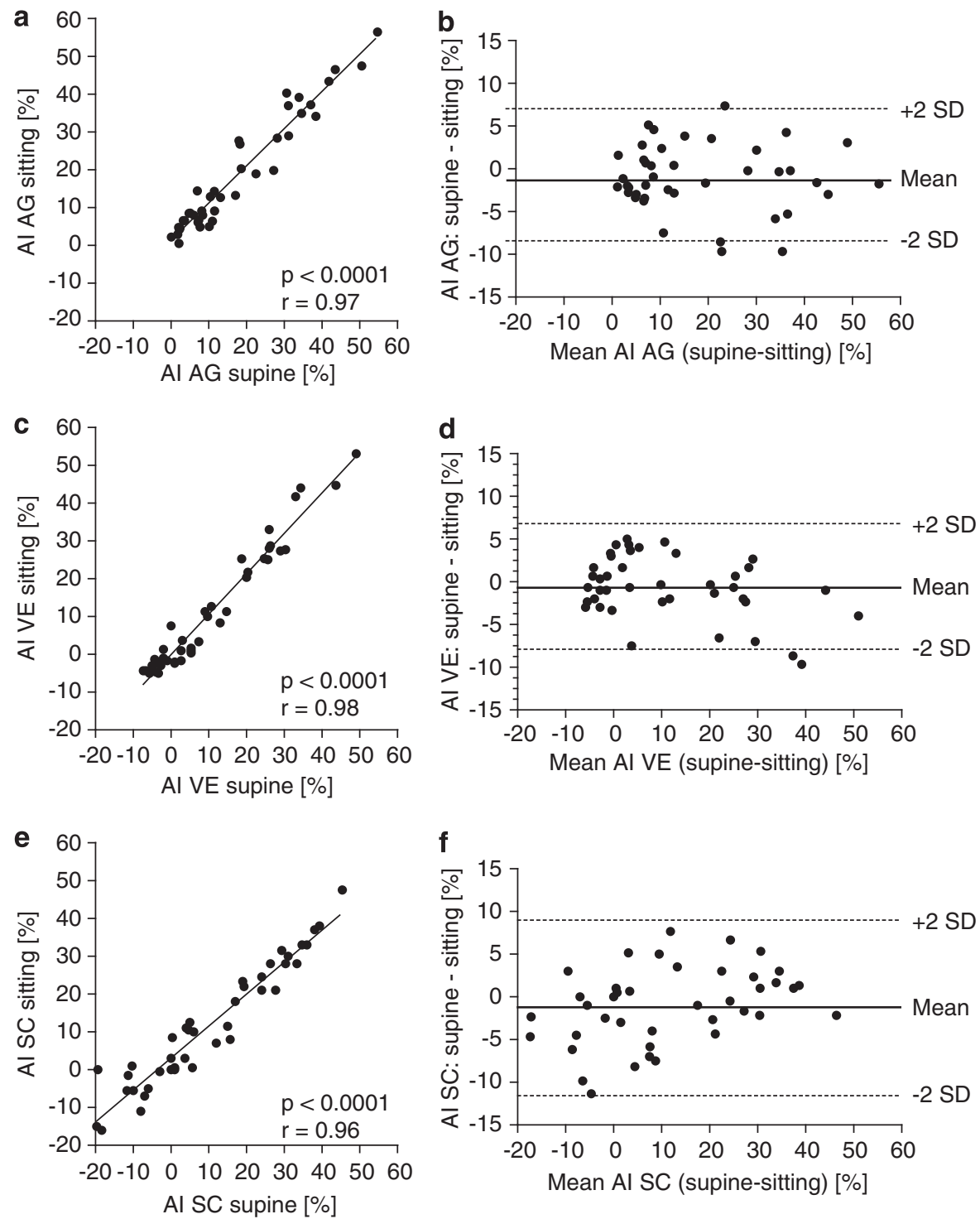

Figure 2 Correlations between sitting and supine measurements of Al obtained by Arteriograph (a), Vascular Explorer (c) and SphygmoCor (e). Bland-Altman plots comparing sitting and supine measurements of Al obtained by Arteriograph (b), Vascular Explorer (d) and SphygmoCor (f). Abbreviations: AG, Arteriograph; Al, augmentation index; VE, Vascular Explorer; SC, SphygmoCor.

peripheral diastolic blood pressure. Consistent with the reports in the literature, ${ }^{11,12}$ in our study subjects mean diastolic blood pressure was 2-3 mm Hg lower than the corresponding sitting pressure.

Hemodynamically, the increase in diastolic blood pressure may lead to an increase in PWV, which closely depends on diastolic blood pressure, particularly in young individuals. ${ }^{13}$ Even though not significant, PWV showed a trend in this direction as well as AI suggesting an earlier return of the reflected wave. A potential increase in AI may have been counteracted by the significantly increasing heart rate with the change of body position, as heart rate changes inversely with AI. However, even after normalizing AI for heart rate, there was no significant difference between both positions. Together, our data are consistent with the concept that orthostasis activates baroreflex response leading to an increased wave reflection as outlined in the study by Reesink et al. ${ }^{12}$ Together, body posture may have a small but not negligible influence on wave reflection. Therefore, a consensus should be reached in which position to measure wave reflection parameters.
We used three different devices to evaluate arterial function: the SphygmoCor device is widely used to measure stiffness surrogates in clinical and epidemiological studies ${ }^{4}$ and it has recently been validated against invasive measurements of PWV. ${ }^{8}$ In addition, we employed the Arteriograph and the Vascular Explorer that determine PWV from PTT, calculated from the decomposition of the aortic pressure wave. ${ }^{10}$ First studies showed a good agreement between parameters obtained oscillometrically (Arteriograph) and those obtained by standard techniques, including SphygmoCor and Complior. ${ }^{5,6}$

In the present study, we found that the wave reflection parameter AI shows a good agreement between all methods, which has been previously shown for SphygmoCor and Arteriograph, ${ }^{5}$ and is a novel finding for the Vascular Explorer.

In contrast, the relationships between the three methods regarding the stiffness marker PWV are poorer. Arteriograph and SphygmoCor measurements of PWV were in line with previous studies showing a moderate correlation with a large scatter with a s.d. of roughly 

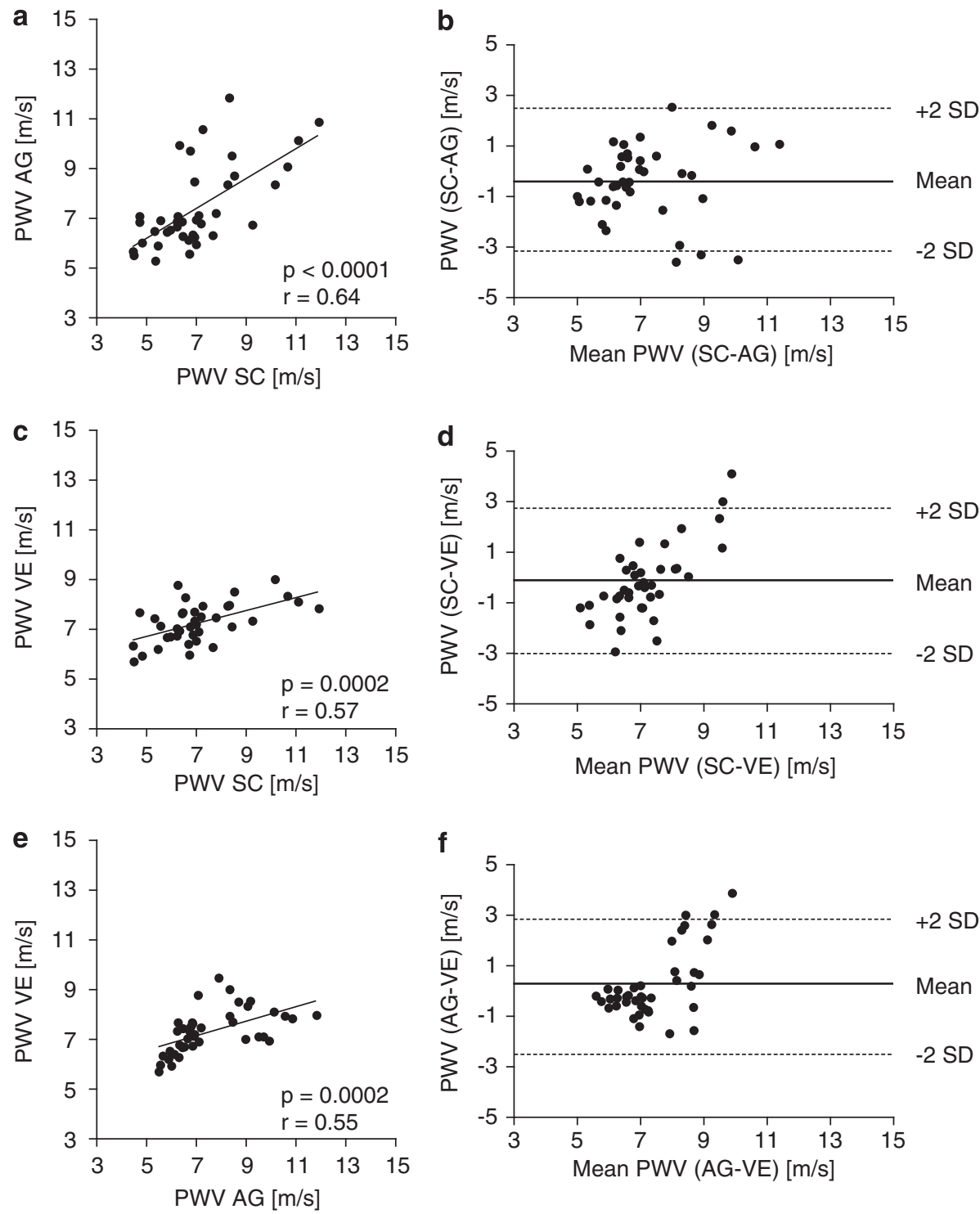

Figure 3 Comparisons of PWV values obtained with the three devices: Arteriograph (AG), Vascular Explorer (VE) and SphygmoCor (SC). There were significant correlations between PWV AG and SC (a, $P<0.0001, r=0.64$ ), PWV VE and SC (c, $P<0.0002, r=0.57$ ), PWV VE and AG (e, $P<0.0002, r=0.55)$. BlandAltman analysis showed good agreement between the methods with the large majority of values in the range of $95 \%$ limits of agreement (b, d, f).

$\pm 1.5 \mathrm{~m} \mathrm{~s}^{-1}$ (Bland-Altman plots). ${ }^{5,6}$ Correlations of PWV obtained by Vascular Explorer with SphygmoCor and Arteriograph also showed correlations with similar s.d. $\left( \pm 1.5 \mathrm{~m} \mathrm{~s}^{-1}\right)$.

There is a suggestion of a systematic bias with overestimation of PWV in the lower range $\left(<8 \mathrm{~m} \mathrm{~s}^{-1}\right)$ and an underestimation of PWV in the higher range $\left(>8 \mathrm{~m} \mathrm{~s}^{-1}\right)$ by the Vascular Explorer. These findings are in line with a recent cross-sectional study suggesting that different techniques to measure PWV may not be used interchangeably. ${ }^{14}$ Prospective long-term studies are required to answer the question whether these new techniques provide robust markers of cardiovascular morbidity and mortality.

There is increasing evidence suggesting that central aortic pressure and indices (AI) are powerful and potentially more robust predictors of risk than brachial pressure. ${ }^{15,16}$ Therefore, measurement of central blood pressure is increasingly used in epidemiological studies. Another important aspect of central blood pressure measurement is that antihypertensive drugs have differential effects on central pressure despite similar effects on brachial pressure. Evidence from a large number of clinical studies has led to the consensus that central blood pressure can be accurately calculated from peripheral pressure waves by the use of transfer functions. ${ }^{17}$ In our study, we found that there was no difference in AI between SphygmoCor and Vascular Explorer, whereas measurements obtained with the Arteriograph were about $7 \%$ higher. To date, the clinical significance of such difference remains unclear. These results emphasize the need to address the issue raised by Boutouyrie et al. ${ }^{18}$ regarding the minimal level of agreement between techniques in order to use them interchangeably.

Measurements of arterial stiffness have recently been included into the recommendation for the management of patients with hypertension. ${ }^{1}$ To date, stiffness measurements are still not widely used in clinical practice. New devices including the Arteriograph and Vascular Explorer offer several advantages for use in clinical routine. For example, these new instruments only require access to the upper arm, are operator-independent and allow fast data acquisition. Although our data suggests that measurements in the sitting position could facilitate the use of arterial stiffness parameters in clinical 

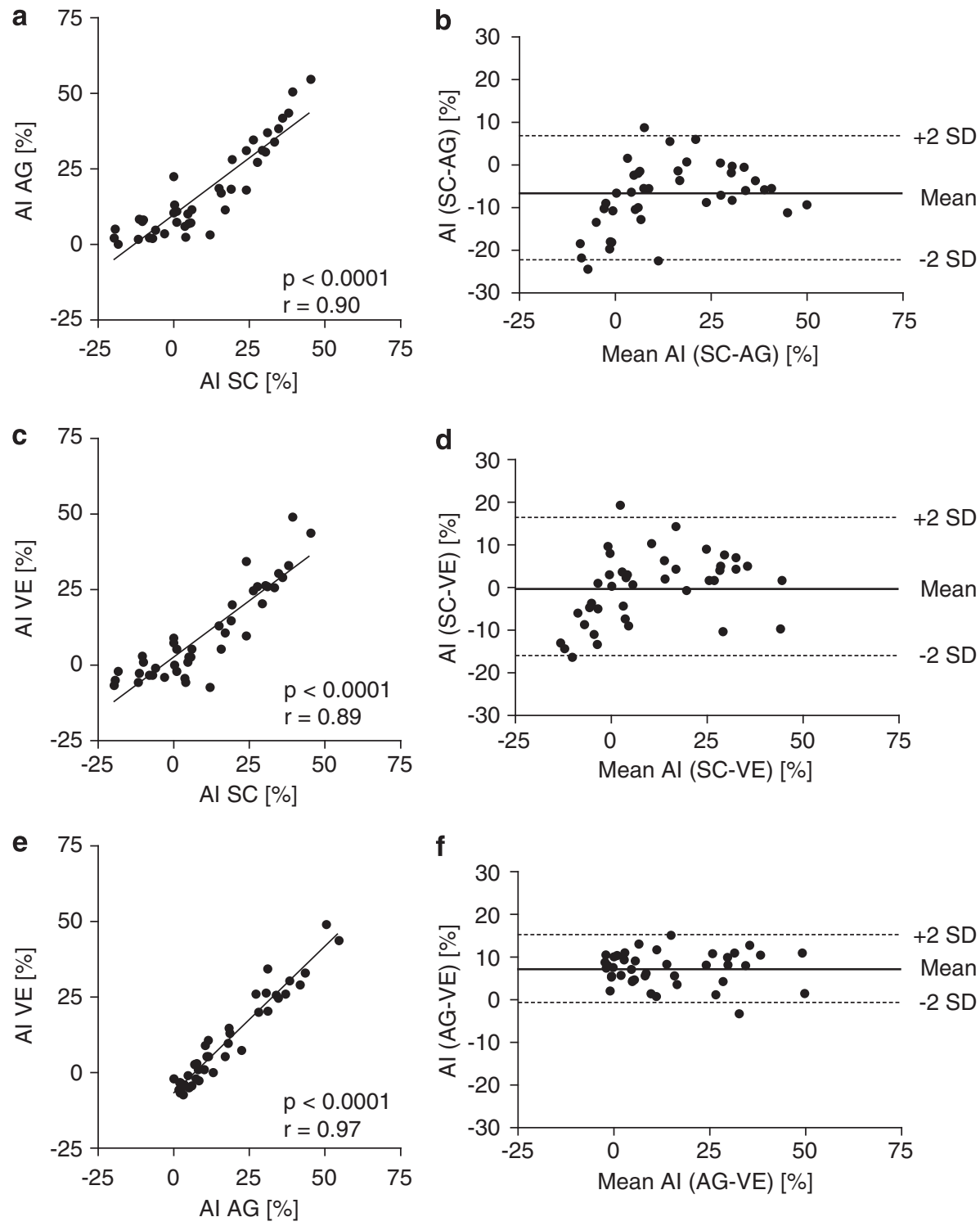

Figure 4 Comparisons of augmentation index (Al) measured with the three devices: Arteriograph (AG), Vascular Explorer (VE) and SphygmoCor (SC). Significant correlations were found between $A G$ and SC (a, $P<0.0001, r=0.90)$, VE and SC (c, $P<0.0001, r=0.89)$, and VE and $A G(e, P<0.0001$, $r=0.97)$. Bland-Altman analysis revealed a good agreement between the methods $(\mathbf{b}, \mathbf{d}, \mathbf{f})$.

routine, potential advantages of simplicity must be weighed against some inaccuracy. For instance, PWV measurements (in particular SphygmoCor vs. the oscillometric devices Arteriograph and Vascular Explorer) could differ by as much as $3 \mathrm{~m} \mathrm{~s}^{-1}$ given the observed correlation between PWV measurements with a large scatter with s.d. of at least $1.5 \mathrm{~m} \mathrm{~s}^{-1}$. However, at present there is no clinical consensus how much scatter is acceptable with respect to PWV measurements.

In conclusion, posture does not appear to significantly influence the stiffness marker PWV. It may have a small but not significant influence on the wave reflection parameter AI. Obtaining stiffness and wave reflection parameters in the sitting position may facilitate their use in clinical routine.

\section{DISCLAIMER}

This paper has not been published elsewhere or is currently under review.

\section{CONFLICT OF INTEREST}

The authors declare no conflict of interest.

\section{ACKNOWLEDGEMENTS}

This study was supported, in part, by grants from the intramural research fund (IFORES) and the Jackstaedt foundation.

1 Mancia G, De Backer G, Dominiczak A, Cifkova R, Fagard R, Germano G, Grassi G, Heagerty AM, Kjeldsen SE, Laurent S, Narkiewicz K, Ruilope L, Rynkiewicz A, Schmieder RE, Boudier HA, Zanchetti A, Vahanian A, Camm J, De Caterina R, Dean V, Dickstein K, Filippatos G, Funck-Brentano C, Hellemans I, Kristensen SD, McGregor K, Sechtem U, Silber S, Tendera M, Widimsky P, Zamorano JL, Erdine S, Kiowski W, Agabiti-Rosei E, Ambrosioni E, Lindholm LH, Viigimaa M, Adamopoulos S, AgabitiRosei E, Ambrosioni E, Bertomeu V, Clement D, Erdine S, Farsang C, Gaita D, Lip G, Mallion JM, Manolis AJ, Nilsson PM, O'Brien E, Ponikowski P, Redon J, Ruschitzka F, Tamargo J, van Zwieten P, Waeber B, Williams B. 2007 Guidelines for the Management of Arterial Hypertension: The Task Force for the Management of Arterial Hypertension of 
the European Society of Hypertension (ESH) and of the European Society of Cardiology (ESC). J Hypertens 2007; 25: 1105-1187.

2 Gurovich AN, Beck DT, Braith RW. Aortic Pulse Wave Analysis is not a surrogate for centra arterial Pulse Wave Velocity. Exp Biol Med (Maywood, NJ) 2009; 234: 1339-1344.

3 O'Rourke MF, Pauca A, Jiang XJ. Pulse wave analysis. Br J Clin Pharmacol 2001; 51 : 507-522.

4 Laurent S, Cockcroft J, Van Bortel L, Boutouyrie P, Giannattasio C, Hayoz D, Pannier B, Vlachopoulos C, Wilkinson I, Struijker-Boudier H. Expert consensus document on arterial stiffness: methodological issues and clinical applications. Eur Heart J 2006; 27: 2588-2605.

5 Baulmann J, Schillings U, Rickert S, Uen S, Dusing R, Illyes M, Cziraki A, Nickering G, Mengden T. A new oscillometric method for assessment of arterial stiffness: comparison with tonometric and piezo-electronic methods. J Hypertens 2008; 26: 523-528.

6 Rajzer MW, Wojciechowska W, Klocek M, Palka I, Brzozowska-Kiszka M, KaweckaJaszcz K. Comparison of aortic pulse wave velocity measured by three techniques: Complior, SphygmoCor and Arteriograph. J Hypertens 2008; 26: 2001-2007.

7 Van Bortel LM, Duprez D, Starmans-Kool MJ, Safar ME, Giannattasio C, Cockcroft J, Kaiser DR, Thuillez C. Clinical applications of arterial stiffness, Task Force III: recommendations for user procedures. Am J Hypertens 2002; 15: 445-452.

8 Weber T, Ammer M, Rammer M, Adji A, O'Rourke MF, Wassertheurer S, Rosenkranz S, Eber B. Noninvasive determination of carotid-femoral pulse wave velocity depends critically on assessment of travel distance: a comparison with invasive measurement. J Hypertens 2009; 27: 1624-1630.

9 Nurnberger J, Keflioglu-Scheiber A, Opazo Saez AM, Wenzel RR, Philipp T, Schafers RF. Augmentation index is associated with cardiovascular risk. $J$ Hypertens 2002; 20 : 2407-2414.
10 Qasem A, Avolio A. Determination of aortic pulse wave velocity from waveform decomposition of the central aortic pressure pulse. Hypertension 2008; 51: 188-195.

11 Jamieson MJ, Webster J, Philips S, Jeffers TA, Scott AK, Robb OJ, Lovell HG, Petrie JC. The measurement of blood pressure: sitting or supine, once or twice? J Hypertens 1990; 8: 635-640.

12 Reesink KD, Hermeling E, Hoeberigs MC, Reneman RS, Hoeks AP. Carotid artery pulse wave time characteristics to quantify ventriculoarterial responses to orthostatic challenge. J Appl Physiol 2007; 102: 2128-2134.

13 Nurnberger J, Dammer S, Opazo Saez A, Philipp T, Schafers RF. Diastolic blood pressure is an important determinant of augmentation index and pulse wave velocity in young, healthy males. J Hum Hypertens 2003; 17: 153-158.

14 Jatoi NA, Mahmud A, Bennett K, Feely J. Assessment of arterial stiffness in hypertension: comparison of oscillometric (Arteriograph), piezoelectronic (Complior) and tonometric (SphygmoCor) techniques. J Hypertens 2009; 27: 2159-2161.

15 Williams B, Lacy PS. Central aortic pressure and clinical outcomes. J Hypertens 2009; 27: $1123-1125$

16 Roman MJ, Devereux RB, Kizer JR, Okin PM, Lee ET, Wang W, Umans JG, Calhoun D, Howard BV. High central pulse pressure is independently associated with adverse cardiovascular outcome the strong heart study. J Am Coll Cardiol 2009; 54: 1730-1734.

17 Agabiti-Rosei E, Mancia G, O'Rourke MF, Roman MJ, Safar ME, Smulyan H, Wang JG, Wilkinson IB, Williams B, Vlachopoulos C. Central blood pressure measurements and antihypertensive therapy: a consensus document. Hypertension 2007; 50: 154-160.

18 Boutouyrie P, Revera M, Parati G. Obtaining arterial stiffness indices from simple arm cuff measurements: the holy grail? J Hypertens 2009; 27: 2159-2161. 